\title{
Impact of Job Design on Employees Psychological Work Reactions (Job Satisfaction \&Turnover Intentions, Organizational Commitment \& Organizational Citizenship Behavior): Empirical Evidence from the Universities of Khyber Pakhtunkhwa
}

\author{
ADIL KHAN \\ Bacha Khan University Charsadda
}

\begin{abstract}
This study explores the effect of job design on employees psychological work reactions i.e. (job satisfaction and commitment) on employee's organizational citizenship behavior $(O C B)$ of public sector universities of Khyber Pakhtunkhwa (KP), Pakistan. The objective of the study was to measure the effect of job characteristics on OCB, satisfaction and commitment and regression analysis predicts that a job characteristic was found as a significant predictor of $O C B$, job satisfaction and job commitment in public sector employee. Result of the study revealed that job characteristic is a significant predictor of $O C B$, job commitment and job satisfaction. Recommendation and suggestions are also included in the study.
\end{abstract}

Keywords: Job Characteristics, OCB, Job Commitment

\section{Introduction}

The work behaviors needed by organizations beyond traditional role-related behaviors (e.g., work output, quantity, quality) are described by the term organizational citizenship behavior (OCB) (Bateman \& Organ, 1983; Smith, Organ \& Near, 1983). Organizational citizenship behaviors are defined as "individual behaviors that are discretionary, not directly or explicitly recognized by the formal reward system, and that in the aggregate promote the effective functioning of the organization" (Organ et al., 2006, p. 3). It is an individual's helpful and cooperative behavior that facilitates the lubrication of the social machinery of the organization, decreases friction, provides flexibility, and leads to efficiency (Bateman \& Organ, 1983; Smith et al., 1983). Obeying organizational rules and regulations, keeping abreast of changes, helping coworkers, and not looking for faults with what the organization is doing are some of the employee behaviors reflecting OCB.

Extra-role behaviors promote the efficiency and effectiveness necessary for productive organizations (Organ et al., 2006). OCB results in higher organizational performance through enhancing coworker and manager productivity, freeing resources up from maintenance functions, improving coordination between team members and across work groups, enhancing the organization's ability to adapt to environmental changes (Podsakoff, MacKenzie, Paine \& Bachrach, 2000). Such a positive relationship between OCB and organizational effectiveness is found in many scientific empirical studies (e.g. Bachrach, Powell \& Bendoly, 2004). The potential positive relationship between OCB and organizational effectiveness caused many research studies to investigate the predictors of OCB. Although some antecedents of OCB such as personalities (e.g., Borman, Penner, 
Allen \& Motowidlo, 2001; Smith et al., 1983), motives (e.g., Finkelstein \& Penner, 2004), leadership (e.g., Wayne, Shore, Bommer \& Tetrick, 2002), and organizational characteristics (e.g., Rhoades \& Eisenberger, 2002) have been thoroughly investigated, few studies have examined the impact of job characteristics on OCB. Research exploring task-related influences upon OCB is needed so as to fill this gap in organizational citizenship behavior research (Organ et al., 2006). Further, few studies have investigated the effects of work attitudes such as job satisfaction and organizational commitment on the relationships between job characteristics and OCBs (Organ et al., 2006).

Therefore, it is important to note that previous research on citizenship behaviors made a limited contribution to organizational behavior literature, since it mainly investigated OCB regardless of its contextual predictors. The means to motivate a job incumbent in a work environment to attain organizational goals is an important investigation area of job design. However few studies examined the relationships among job design, job satisfaction, organizational commitment, and citizenship behaviors. This dissertation extends citizenship behaviors research by combining job design with job satisfaction and organizational commitment to explain OCB. The aim of the present study is to analyze the relationships between job characteristics and OCBs by means of job satisfaction and organizational commitment. The present study provide important information regarding the relative effect of job characteristics on OCBs, the influences of job characteristics on work attitudes, work attitudes' predictive role on OCBs, and the interplay among these concepts. The objective of the study is to find out the effect of job characteristics on OCB, organizational commitment and job satisfaction.

\section{Literature Review}

\subsection{Job Characteristics and Organizational Citizenship Behaviors}

The existence of possible relationships between job characteristics and OCBs was mentioned by Katz (1964) before either of these constructs was formally conceptualized. Katz emphasized the importance of the work context or work environment enhanced with job characteristics where employees perform beyond role requirements for accomplishments of organizational functions. Providing work environment with intrinsic motivation is considered as a responsibility of an organization towards its employees. According to Katz, for an intrinsically motivated employee "Gratifications accrue from accomplishments, from the expression of his own abilities, from the exercise of his own decisions" (p. 141). The work environment that will lead to intrinsic motivation is also described by Katz: The job must "provide sufficient skill, variety, sufficient complexity, and sufficient challenge to engage the abilities of the worker" (p.141). According to Katz, the quantity and quality of work increase through demanding jobs with higher responsibility, since such jobs foster intrinsic motivation. Job enrichment or redesign is a way of creating work environments that create a context appropriate for the development of innovative and spontaneous behaviors. Such behaviors were later called organizational citizenship behaviors.

Although there has been much research about the effects of task-related variables on work related outcomes, the relationships between job characteristics and the multidimensional OCB construct have not been explored sufficiently (e.g., Farh, Podsakoff \& Organ, 1990). Empirical research evidence, especially studies examining substitutes for leadership, supports correlations between some job characteristics and OCB (Podsakoff et al., 1993; 
Podsakoff et al., 1996b), however, the extent and nature of these relationships are not clear (Organ et al., 2006). This dissertation is a conscious attempt to remedy this limitation by investigating how job scope as a composition of job characteristics predicts OCBs together with the influences of work attitudes of job satisfaction and organizational commitment. Employees' sense of ownership and responsibility for work outcomes are enhanced through the job characteristic of autonomy (Hackman \& Oldham, 1980). Thereby, their willingness to exhibit OCB is increased in order to accomplish the task (Organ et al., 2006). Greater control through autonomous tasks is associated with increased OCB. A job is important to a job incumbent if it has job characteristics of identity, variety, and significance (Hackman \& Oldham, 1980). These job characteristics are likely to influence OCB by increasing employees' perceptions of the meaningfulness of their work (Organ et al., 2006). Employees motivated as a result of enhanced jobs would expend more energy and effort in the form of OCB.

The knowledge about the results of effort conveyed to employees through feedback is expected to have a biggest effect on employee performance (Hackman \& Oldham, 1980). Feedback is important for people committed to taks accomplishment. Task feedback is expected to be more closely related to helping others with work-related problems and the aspect of civic virtue that involves making constructive suggestions about how to improve task performance, since these behaviors require greater knowledge of the factors contributing to task accomplishment than other forms of OCB (Organ et al., 2006). Therefore, the following hypothesis is proposed.

$\mathrm{H}_{l}$ : Job characteristics significant predict organizational citizenship behaviors.

\subsection{Job Characteristics and Job Satisfaction}

Job satisfaction happens and the person is more likely to perform a job when the characteristics of the jobs are compatible with the needs of the person (Salancik \& Pfeffer, 1977). Jobs that fulfill a person's needs are satisfying and those that do not are not satisfying. Salancik and Pfeffer stated that If the person is satisfied with his/her job, it is presumably because the job has characteristics compatible with his/her needs. If the person is unhappy with his/her job, it is because the job presumably not satisfying his/her needs (Salancik \& Pfeffer, 1977, p. 428). Locke pointed out that A job is not an entity but complex interrelationships of tasks, roles, responsibilities, interactions, incentives and rewards. Thus, an understanding of job attitudes requires that the job be analyzed in terms of its constituent elements (Locke, 1976, p. 1301).

Katz (1964) considered a link between job satisfaction and job enlargement. While he claimed that the development of intrinsic job satisfaction was essential for the motivational pathway to high productivity, he suggested structural changes in tasks such as job enlargement for securing higher motivation to produce. The job characteristics model of work motivation has been the dominant theoretical framework for understanding an employee's reaction to the core dimensions of the job (Fried \& Ferris, 1987). Job satisfaction is the individual outcome that is associated to the motivational potential of job scope. According to the job characteristics model, employees are satisfied when they perceive their work to be meaningful through skill variety, task identity, and task significance, when they experience responsibility for the results of their work through autonomy, and when they have knowledge about the results of their work through feedback. Strong empirical support exists for the relationships between the job 
characteristics and job satisfaction (Boonzaier et al., 2001). Researchers such as Kemp and Cook (1983), Champoux (1991), and Renn and Vanderberg (1995) report that the job characteristics strongly correlate with satisfaction. Given these findings, the following hypothesis is proposed:

\section{$\mathrm{H}_{2}$ : Job characteristics predict job satisfaction.}

\subsection{Job Characteristics and Organizational Commitment}

The congruence between the characteristics of the individual and of the organization itself is important for researchers examining the relationship between job characteristics and organizational commitment, since such an organization-person fit may have an impact on attitudes and behavior of job incumbents. It is argued that an experience that is congruent with the employees' values or needs will affect organizational commitment. The greater the fit between the person and the organization, the greater the commitment to the organization (Finegan, 2000). Person-job fit had strong correlations with organizational commitment (Kristof-Brown et al., 2005). Organizational commitment is influenced by person-job fit. Job characteristics are considered as antecedents of organizational commitment as a result of the meta-analysis of Mathieu and Zajac (1990). Job characteristics and organizational commitment exhibited positive correlations in this study. Job scope correlated more highly $(r=.50)$ and more consistently with organizational commitment than did any of the job characteristics (Mathieu \& Zajac, 1990). Complex and enriched jobs are likely to yield higher organizational commitment (Steers, 1977). Enhanced job characteristics, particularly in an aggregate form, offer promise as an antecedent to the development of organizational commitment (Mathieu \& Zajac, 1990). Given these findings, the following hypothesis is proposed:

$\mathrm{H}_{3}$ : Job characteristics predict organizational commitment.

\subsection{Job Satisfaction and Organizational Citizenship Behaviors}

OCB is more likely than core task performance of correlating with job satisfaction, because job satisfaction find expression in behavior only to the extent that such behavior is not constrained by ability or external forces (Organ et al., 2006). Logic for expecting greater OCB as a result of job satisfaction is grounded in concepts of social exchange. Employees tend to reciprocate toward those who benefit them with citizenship behaviors if they are satisfied (Blau, 1964; Organ et al., 2006). Job satisfaction has been accepted as a strong predictor of citizenship behavior for many years (Organ \& Lingl, 1995; Williams \& Anderson, 1991). According to Organ and Lingl (1995), 15 studies resulted in a significant statistical relationship between OCB and job satisfaction. The importance of satisfaction for OCB is supported by Williams and Anderson (1991). Employees who are satisfied with their jobs will be more likely to perform more discretionary behaviors that benefit the organization than those who are not. The construct of organizational citizenship behavior was conceptualized by Bateman and Organ (1983) with a belief that job satisfaction influenced one's work behaviors that are extra role in nature. In addition, Organ (1988a) suggested that job satisfaction and citizenship behavior were inextricably linked in a robust bond. However, the complex nature of such a relationship has to be noted since different measures of job satisfaction share different correlations with OCB (Moorman, 1991) as discussed in the introduction chapter of the present study. The meta-analytic review of Organ and Ryan (1995) found positive correlations between job satisfaction and OCB in 28 studies. A more recent meta-analysis of Judge and his colleagues (2001) 
resulted with similar findings. The evidence appears to support the associations between job satisfaction and OCB when job satisfaction is considered as a major motivational condition for much OCB (Organ et al., 2006). The following hypothesis is proposed:

$$
H_{4}: \text { Job satisfaction predicts organizational citizenship behaviors. }
$$

\subsection{Organizational Commitment and Organizational Citizenship Behaviors}

Individual forfeit for the organization can be encouraged through the attitude of commitment (Wiener, 1982). Scholl (1981) and Wiener (1982) proposed models of commitment supporting relationships with OCBs. Commitment is described in Scholl's (1981) model as a stabilizing force that acts to maintain behavioral direction when expectancy/equity conditions are not met and do not function. According to this definition, commitment has at least four sources: investments, reciprocity, lack of alternatives, and identification. Significant interrelationship between organizational commitment and OCBtype behaviors is supported by O'Reilly and Chatman (1986). They found that dimensions of organizational commitment such as identification and internalization were positively related to OCB-type behaviors. In his study, Schappe (1998) considered job satisfaction, procedural justice, and organizational commitment together to investigate their influence on OCB. Organizational commitment had the only significant relationship to OCB ( $\boldsymbol{\beta}=$ $.36, p<.001)$ when considered with job satisfaction and procedural justice simultaneously. Organizational commitment emerged as a significant predictor of OCB in this study. Organizational commitment is a determinant of OCB since the latter describes behaviors that occur with little expectation of formal organizational rewards for performance (Williams \& Anderson, 1991). In Wiener's (1982) model, organizational commitment causes behaviors that (a) reflect personal forfeit made for the organization, b) do not depend primarily on reinforcements or punishments, and (c) indicate personal preoccupation with the organization. Additional support is found for commitment as an antecedent of OCB since the characteristics mentioned in the model of Wiener (1982) identify OCB. Mathieu and Zajac (1990) argued that committed employees were more likely to exhibit citizenship behaviors, which was often important for a competitive organization. Given these findings, the following hypothesis is proposed:

$\mathrm{H}_{5}$ : Organizational commitment predicts organizational citizenship behaviors.

\section{Research Methodology}

\subsection{Population}

The total population of male and female faculty members including (lecturers, assistant professors, associate professors and professors) in public sector universities was 1616. According to Kerlinger \& Lee (2000) survey is an appropriate technique of data collection when researcher has to investigate a large size of population geographically spread over a vast area.

\subsection{Sample Size Determination}

The sample size was resolved with the assistance of recipe of (Yamane, 1967) for limited populace. Final sample was 316 faculty members of public sector universities of KPK, Pakistan.

Table 1: Sample Size Determination

\begin{tabular}{lcc}
\hline \multicolumn{2}{l}{ Population in Public Sector Universities (Faculty) } & Total \\
\hline $\mathrm{n}=\mathrm{N} / 1+\mathrm{N}^{*}(\mathrm{e})^{2} \mathrm{n}=1616 / 1+1616^{*}(.05)^{2}$ & $\mathrm{n}=316$ \\
\hline Khan & 43 & ISSN: $2520-0739$
\end{tabular}




\subsection{Sampling Frame}

Sampling is a procedure to select adequate amount of elements from the whole population (Sekaran, 2003). For understanding the characteristics or properties of the sample, the researchers simplify these characteristics to the entire population. For data gathering from faculty members of universities of KP, Pakistan the probability sampling technique i.e. stratified random sampling was used. In statistical surveys when subpopulations within an overall population vary, it is advantageous to sample each subpopulation (stratum) independently. The researcher used proportionate allocation method for sampling fraction in each of the strata that is proportional to that of the total population. The proportional allocation technique is defined as follows:

$$
n_{i}=\frac{n}{N} \times N_{i}
$$

Where:

$n=$ Required sample size

$N=$ Total number of faculty members in the university departments

$N_{i}=$ number of faculty members employed in the university departments.

$n_{i}=$ number of selected faculty from the university departments.

Following table shows the detail of the respondents selected via proportionate allocation method.

Table 2: Proportionate Allocation Method

\begin{tabular}{llcc}
\hline S \# & Public (Faculty) & Formula ni $=\mathbf{N i * n} / \mathbf{N}$ & Sample (ni) \\
\hline $\mathbf{1}$ & University of Peshawar & $\mathrm{ni}=496 * 316 / 1616$ & 97 \\
$\mathbf{2}$ & Islamia College Peshawar & $\mathrm{ni}=170 * 316 / 1616$ & 33 \\
$\mathbf{3}$ & Malakand university & $\mathrm{ni}=151 * 316 / 1616$ & 30 \\
$\mathbf{4}$ & Frontier Women University & $\mathrm{ni}=123 * 316 / 1616$ & 24 \\
$\mathbf{5}$ & Kohat University & $\mathrm{ni}=158 * 316 / 1616$ & 31 \\
$\mathbf{6}$ & Abdul Wali Khan University & $\mathrm{ni}=185 * 316 / 1616$ & 36 \\
$\mathbf{7}$ & Gomal University D.I.Khan & $\mathrm{ni}=153 * 316 / 1616$ & 30 \\
$\mathbf{8}$ & Hazara University & $\mathrm{ni}=135 * 316 / 1616$ & 26 \\
$\mathbf{9}$ & Shringle University & $\mathrm{ni}=45 * 316 / 1616$ & 9 \\
& Total & & $\mathbf{3 1 6}$ \\
\hline
\end{tabular}

The final sample of male and female faculty members in public sector universities including (lecturers, assistant professors, associate professors and professors) in University of Peshawar, Islamia College University, Malakand University, Frontier Women Univesity, Kohat University, Abdul Wali Khan Univesity, Gomal University, Hazara University and Shringal Univesity were 97, 33, 30, 24, 31, 36, 30, 26 and 9 respectively.

\subsection{Data Collection}

Before the administration of questionnaires to the target sample, a pilot study was conducted to ascertain the reliability of the constructs of the instrument. The objective of the pilot study was to ascertain, whether the questionnaire is easy to understand and respond by the respondents or otherwise. Sixty (60) questionnaires were distributed among four universities including two public sector universities. Each university was administered with 30 questionnaires. The responses received helped in improving the 
questionnaire in terms of sentence structure and phrasing of items, wherever needed. Few of the items were even removed from the questionnaires. Furthermore, responses across cities were compared to ensure that the responses are not significantly different. Overall results revealed no significant difference in the means of the different constructs in the study. After the pilot study amid the faculty members of public sector universities including (lecturers, assistant professors, associate professors and professors) total 316 questionnaires were distributed and 290 usable questionnaires were returned the response rate was $92 \%$.

\subsection{Measurement Instrument}

For the data collection researcher used questionnaire. All items of measurement scale were measured on 5 point Likert Scale ( $1=$ strongly disagree to $5=$ strongly agree). Following is the detail.

\subsubsection{Job Characteristics}

\subsubsection{Skill variety}

The measurement items of skills variety were taken from the study of (Hackman \& Oldham's, 1975).

\subsubsection{Task identity}

The measurement items of skills variety were taken from the study of (Hackman \& Oldham's, 1975).

\subsubsection{Task significance}

The measurement items of skills variety were taken from the study of (Hackman \& Oldham's, 1975).

\subsubsection{Autonomy}

The measurement items of skills variety were taken from the study of (Hackman \& Oldham's, 1975).

\subsubsection{Feedback from the job itself}

The measurement items of skills variety were taken from the study of (Hackman \& Oldham's, 1975).

\subsubsection{Job Satisfaction Scale}

The measurement items of job satisfaction were taken from the study of (Spector, 1985).

\subsubsection{Organizational Citizenship Behavior}

The measurement item of organizational citizenship behaviour is taken from the study of (Lee and Allen, 2002)

\subsubsection{Organizational Commitment}

The measurement items of organizational commitment were tajen from the study of (Mayers and Allen, 1991).

\section{Data Analysis}

\subsection{Demographic Variables of Respondents (Faculty)}

\section{Table 3: Gender wise detail of the sample}




\begin{tabular}{lcc}
\hline Gender & Frequency & Percent \\
\hline Male & 208 & 71.7 \\
Female & 82 & 28.3 \\
Total & 290 & 100.0 \\
\hline
\end{tabular}

Table 3 Depict cumulative percentages as well number of male and female respondents. Entire strength of Male participators 208 out of 290 participators representing $71.7 \%$ of the total whereas; female showed 82 out of 290 participators that described $28.3 \%$ of the entire sample.

Table 4: Age wise detail of the sample

\begin{tabular}{lcc}
\hline Age & Frequency & Percent \\
\hline $25-35$ years & 174 & 60.0 \\
36-45 years & 38 & 13.1 \\
46 and above & 78 & 26.9 \\
Total & 290 & 100.0
\end{tabular}

Table 4 description is ages and frequency distribution. The ages of 25-35 years describes 174 out of 290 participators that described $60 \%$ of entire sample 290. From 36-45 years of age's group members represents 38 out of 290 participators that portray $13.1 \%$ of the total sample 290. From 46 and above years of ages group participators describe 78 out of 290 members that representing 26.9\% of the entire sample 290 .

Table 5: Designation wise detail of the sample

\begin{tabular}{lcc}
\hline Designation & Frequency & Percent \\
\hline Lecturers & 167 & 57.6 \\
Assistant Professors & 78 & 26.9 \\
Associate Professors & 25 & 8.6 \\
Professors & 20 & 6.9 \\
\hline Total & 290 & 100.0 \\
\hline
\end{tabular}

Table 5 represents the designation of the participants. Lecturers, Assistant Professors Associate Professors and Professors were participate in the study survey and were found 167, 78, 25 and 20 respectively out of 290 members. Furthermore, it represents the percentage of $57.6 \%, 26.9 \%, 8.6 \%$ and $6.9 \%$ respectively.

\subsection{Confirmatory Factor Analysis and Structure Equation Modelling}

The content and face validity of measurement instrument i.e. (questionnaire) was checked by veteran research scholars. The scholars in this regard validated the questionnaire and gave the permission for data collection. For convergent/construct validity the particular model of the research study was examine through structural equation Model (SEM) and confirmatory factor analysis (CFA). The CFA is performed on the data because some of the questionnaire items were constructed. For constructed measurements items the CFA is performed (Usluel etal., 2008). For examining model fitness study used seven fit indices namely (X²/df, GFI, AGFI, NNFI, CFI, RMSR, RMSEA).

\subsubsection{Structural Analysis Full Factor Model}




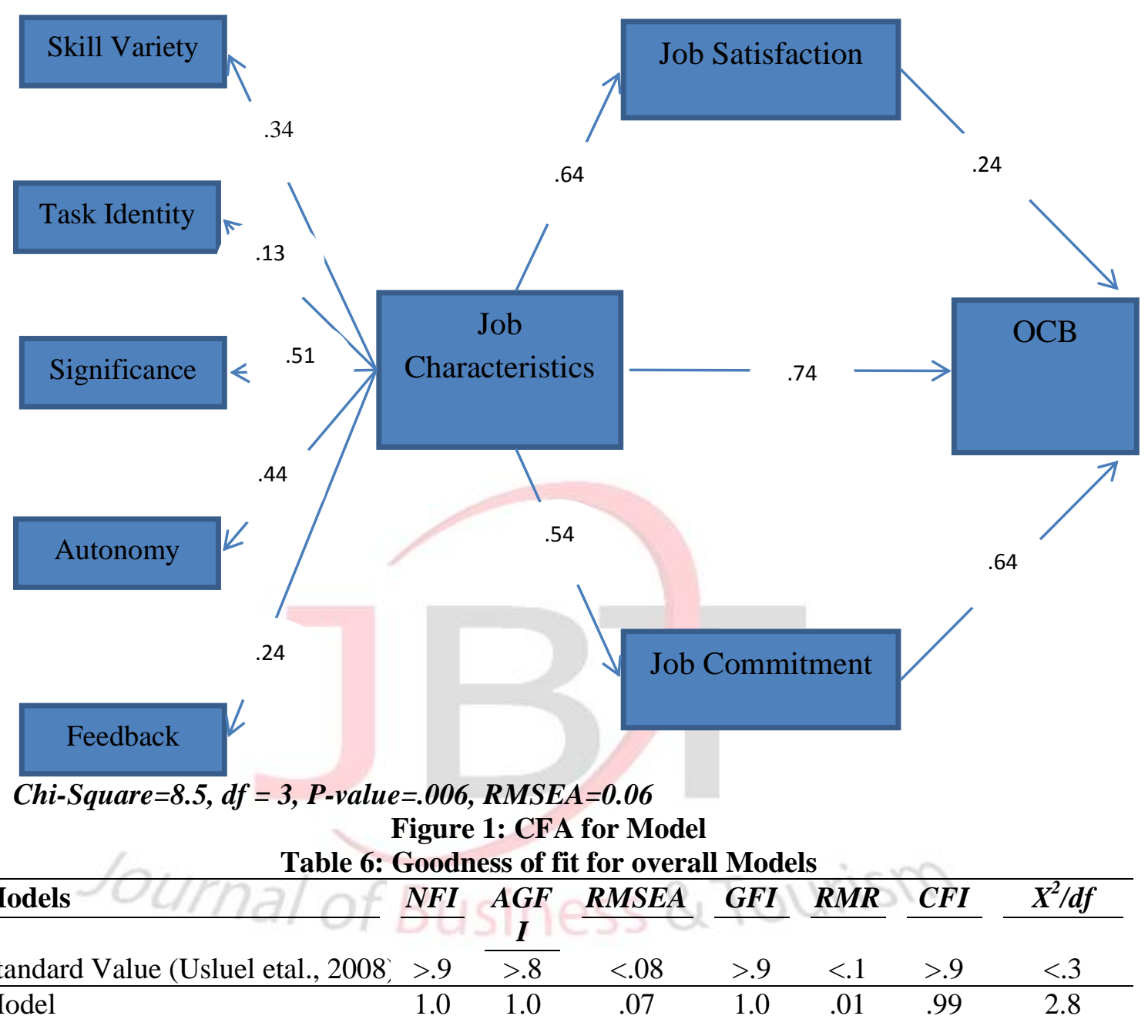

$X^{2}=$ chi-sqr, $d f=$ degree of freedom, GFI = goodness of fit index $A G F I=R M R=$ root mean error of residuals $R M S E A=$ root means sqr error of approximation, $C F I=$ comparative fit index, NFI = normed fit index

Seven fit aforementioned indices i.e. (X²/d.f, GFI, AGFI, NNFI, CFI, RMSR, RMSEA) were used for checking the goodness of fit for all alternative models. The result of CFA's analysis exhibits the uniqueness of variables. The result of all the alternative models depicted that all values have their own significant loadings and all alternative models are good fit.

\subsection{Convergent Validity}

4.3.1 Convergent Validity of Model i.e. Job Characteristics and OCB 


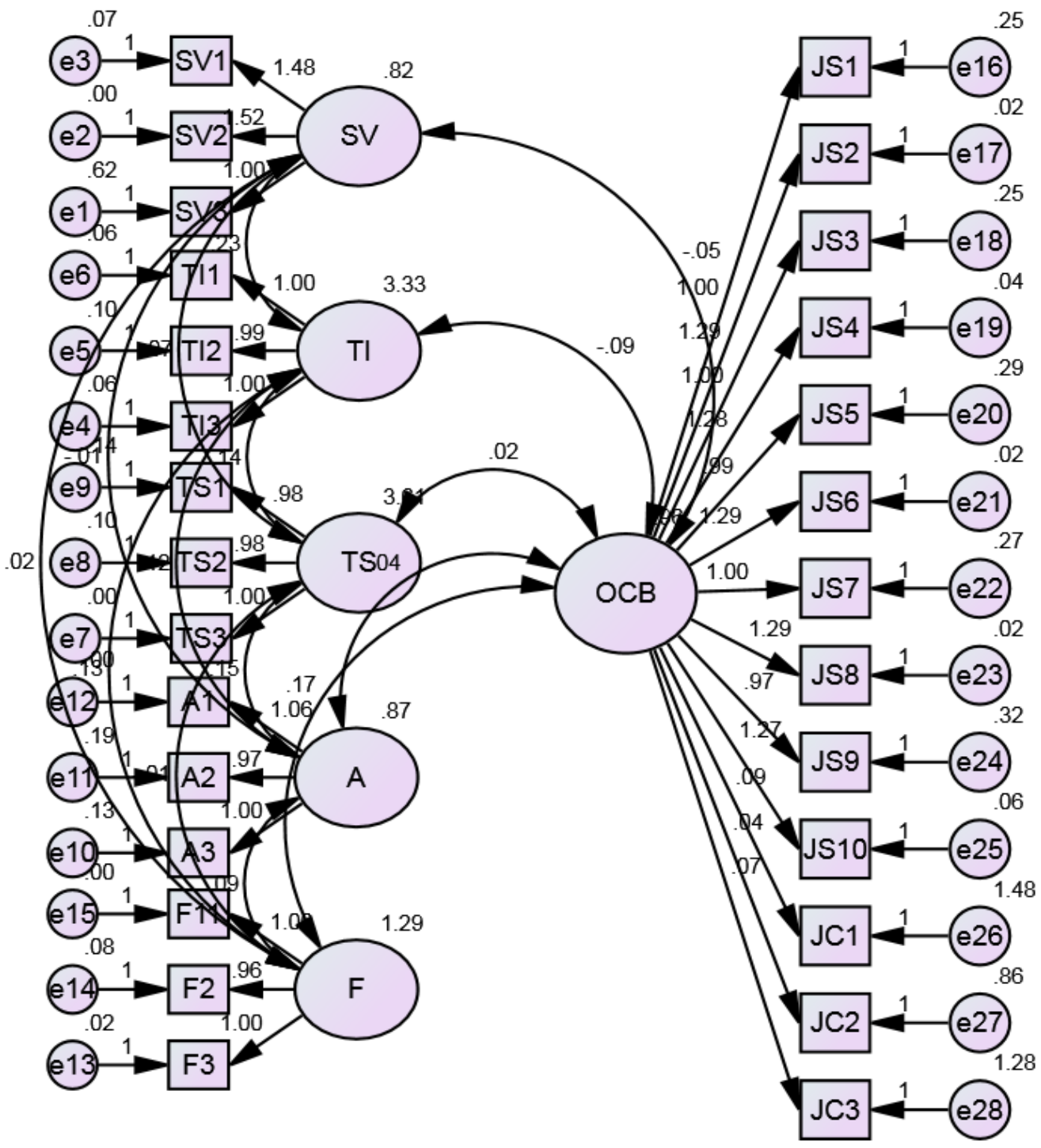

Table 7: Model Validity Measures

\begin{tabular}{lcccccc}
\hline & CR & AVE & MSV & MaxR(H) & JC & OCB \\
\hline Job Characteristics & 0.941 & 0.844 & 0.019 & 1.002 & $\mathbf{0 . 9 1 9}$ & \\
OCB & 0.993 & 0.978 & 0.019 & 0.993 & $0.139^{*}$ & $\mathbf{0 . 9 8 9}$ \\
\hline
\end{tabular}

According to aforementioned table all the seven fit indices are in good statistical range (Usluel et al., 2008). In addition to that no validity issue has been found because all the values of validity are in good statistical range (Hu \& Bentler, 1999; Gaskin \&s Lim, 2016).

4.3.2 Convergent Validity of Model i.e. Job Satisfaction, Job Characteristics, OCB 


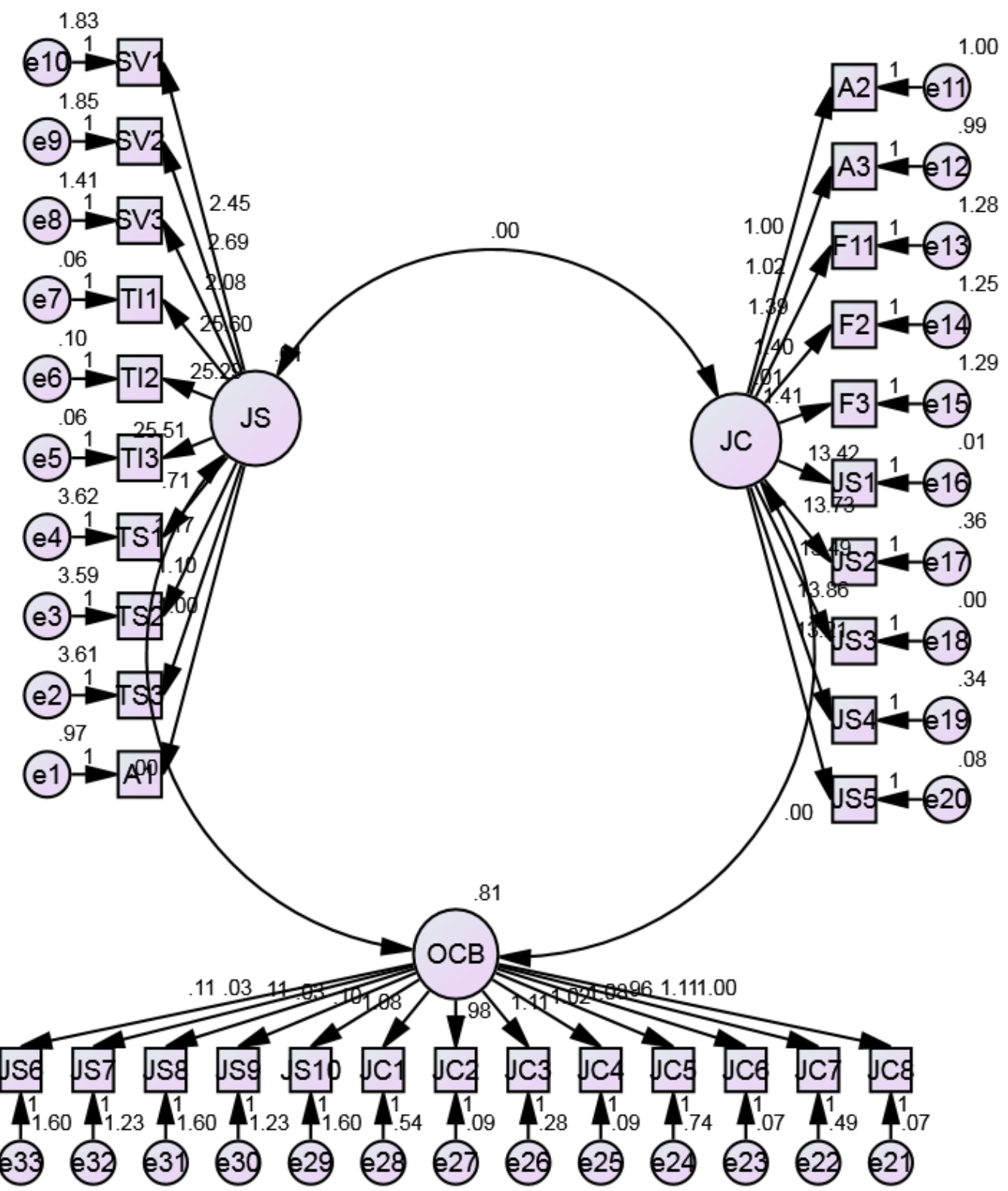

Table 8: Model Validity Measures

\begin{tabular}{lccccccc}
\hline & CR & AVE & MSV & MaxR(H) & JS & JC & OCB \\
Job Satisfaction & 0.941 & 0.844 & 0.019 & 1.002 & $\mathbf{0 . 9 1 9}$ & & \\
Job Commitment & 0.993 & 0.978 & 0.019 & 0.943 & $0.139^{*}$ & $\mathbf{0 . 9 6 5}$ & \\
OCB & 0.992 & 0.978 & 0.007 & 1.000 & 0.951 & 0.041 & $\mathbf{0 . 9 8 9}$ \\
\hline
\end{tabular}


According to aforementioned table all the seven fit indices are in good statistical range (Usluel etal., 2008). In addition to that no validity issue has been found because all the values of validity are in good statistical range (Hu \& Bentler, 1999; Gaskin \& Lim, 2016).

\section{Discussion}

This study explores the effect of job design on employees psychological work reactions on employees of public and private universities of Khyber Pakhtunkhwa (KP), Pakistan. The population of the study was comprised of faculty members of public universities located in diverse location of KP, province of Pakistan. Entire strength of Male participators 208 out of 290 participators representing $71.7 \%$ of the total whereas; female showed 82 out of 290 participators that described $28.3 \%$ of the entire sample. The ages of $25-35$ years describes 174 out of 290 participators that described $60 \%$ of entire sample 290 . From $36-45$ years of age's group members represents 38 out of 290 participators that portray $13.1 \%$ of the total sample 290. From 46 and above years of ages group participators describe 78 out of 290 members that representing 26.9\% of the entire sample 290. Lecturers, Assistant Professors Associate Professors and Professors were participate in the study survey and were found $167,78,25$ and 20 respectively out of 290 members. Furthermore, it represents the percentage of $57.6 \%, 26.9 \%, 8.6 \%$ and $6.9 \%$ respectively.

The Simple linear regression was performed to check the effect of job characteristics and OCB. Regression analysis predicts that a job characteristic is a significant predictor of OCB and account $85 \%$ variation in the response variable. According to the statistical value of $t$ which is above 2 concluding a result that job characteristics has significant positive effect on OCB. The result of the study was consistent with the previous studies of (Alessandri, Borgogni, and Truxillo, 2014; Alkire and Avey, 2013; Al-Zoubi, 2012; Artz and Kaya, 2014; Baro, Fyneman and Zoukemefa, 2013; Bouckenooghe, Raja and Butt, 2013; Cassidy, McLaughlin and McDowell, 2014; Chan and Qiu, 2011). Structure equation model was performed to check the effect of job satisfaction on OCB. Result of regression analysis predicts that a job satisfaction is a significant predictor of OCB and account $77.8 \%$ variation in the response variable. According to the statistical value of $t$ which is above 2 concluding a result that job satisfaction has significant positive effect on OCB. The result of the study was consistent with the previous studies of (Alessandri, Borgogni, and Truxillo, 2014; Alkire and Avey, 2013; Al-Zoubi, 2012; Artz and Kaya, 2014; Baro, Fyneman and Zoukemefa, 2013; Bouckenooghe, Raja and Butt, 2013; Cassidy, McLaughlin and McDowell, 2014; Chan and Qiu, 2011). The job commitment and OCB was measured and found that a job commitment is a significant predictor of OCB and account $44.6 \%$ variation in the response variable. According to the statistical value of $\mathrm{t}$ which is above 2 concluding a result that job commitment has significant positive effect on OCB. The result of the study was consistent with the previous studies of (Alessandri, Borgogni, and Truxillo, 2014; Alkire and Avey, 2013; Al-Zoubi, 2012; Artz and Kaya, 2014; Baro, Fyneman and Zoukemefa, 2013; Bouckenooghe, Raja and Butt, 2013; Cassidy, McLaughlin and McDowell, 2014; Chan and Qiu, 2011).

\subsection{Summary of Hypotheses}

\begin{tabular}{|l|l|c|}
\hline S\# & Hypotheses & Accept/Reject \\
\hline 1 & H1: Job characteristics has significant effect on OCB & Accept \\
\hline 2 & H2: Job characteristics has significant effect on job satisfaction & -do- \\
\hline 3 & H3: Job characteristics has significant effect on job commitment & -do- \\
\hline
\end{tabular}


\begin{tabular}{|l|l}
\hline 4 & H4: Job satisfaction has significant effect on job commitment \\
\hline
\end{tabular} -do-

\subsection{Findings of the Study}

1. In public sector universities the entire strength of Male participators 208 out of 290 participators representing $71.7 \%$ of the total whereas; female showed 82 out of 290 participators that described $28.3 \%$ of the entire sample.

2. The ages of 25-35 years describes 174 out of 290 participators that described $60 \%$ of entire sample 290. From 36-45 years of age's group members represents 38 out of 290 participators that portray $13.1 \%$ of the total sample 290. From 46 and above years of ages group participators describe 78 out of 290 members that representing $26.9 \%$ of the entire sample 290.

3. Lecturers, Assistant Professors Associate Professors and Professors were participate in the study survey and were found 167, 78, 25 and 20 respectively out of 290 members. Furthermore, it represents the percentage of $57.6 \%, 26.9 \%, 8.6 \%$ and $6.9 \%$ respectively.

4. Regression analysis predicts that a job characteristic is a significant predictor of OCB and account $85 \%$ variation in the response variable.

5. Result of regression analysis predicts that a job satisfaction is a significant predictor of OCB.

6. The regression amid job commitment and OCB was measured and found that a job commitment is a significant predictor of OCB.

\subsection{Conclusion}

This study explores the impact of job design on employees psychological work reactions i.e. (job satisfaction and commitment) on employees OCB of public sector universities of Khyber Pakhtunkhwa (KP), Pakistan. The objective of the study was to measure the effect of job characteristics on OCB, satisfaction and commitment and regression analysis predicts that a job characteristic was found as a significant predictor of OCB, job satisfaction and job commitment in public sector employee. The study concluded that each position in both public universities should have a formal job description. Employees should know up front to whom they report, what kinds of decisions they are allowed to make, and what is expected each day. Faculty members of both public sector universities should receive appropriate training in management and people skills. Most employees leave a company because of a poor relationship with their boss, not because of the company. Faculty members of both public sector universities conduct employee satisfaction surveys often. Ask employees what they want more in their positions, and what they want less. Then, do what you can to show them you were listening. Make sure universities have a formal and consistent orientation program for all faculty members of both public and private sector universities. Faculty members of public sector universities will feel more like a part of the team if there is interest demonstrated in their success from the onset. Faculty members of public sector universities want to know what is going on inside university. Make an effort to keep them informed of any changes being made. Let them hear it from their managers first, and it will create a sense of loyalty and trust. Employees interested in advancement will want to learn new things and create value in their position. Provide those opportunities either with internal or outside education, 
sponsored by the company. Make their professional development a part of their review process, goals and objectives.

\subsection{Limitations}

There are certain limitations of this study. One imperfection originates from the quantitative methodological worldview of factual generalizability, is that, the most quantitative studies start with an obscure thought of an objective populace which is not very much characterized in a large portion of the exploration concentrates on and even they will probably have an unequivocal open populace (Kerlinger \& Lee, 2000). Due to moderate sample size on cross sectional basis this study is limited in terms of factual generalizability and the result might be biased. Moreover, this study has also limitation pertaining to the issue of analytical generalizability because the researcher didn't used confirmatory strategies in terms of checking all the assumptions of the implemented multiple regression tests.

\subsection{Future Area for Research}

The area for additional and further research is an in-depth examination of university both public and private university teachers on all around Pakistan to take hold of some of the other factors contributing towards the teachers job commitment. In future, the present hypotheses should be studied with some moderating and mediating variables in numerous samples from all provinces of Pakistan on longitudinal basis.

\section{References}

Allison, B. J., Voss, R. S., \& Dryer, S. (2001). Student classroom and career success: The role of organizational citizenship behavior. Journal of Education for Business, 3, $282-288$

Alotaibi, A. G. (2001). Antecedents of organizational citizenship behavior: A study of public personnel in Kuwait. Public Personnel Management, 30, 363-376.

Arvey, R. D., Bouchard, T. J., Segal, N. L., \& Abraham, L. M. (1989). Job satisfaction: Environmental and genetic components. Journal of Applied Psychology, 74(2), 187-192.

Aycan, Z., Kanungo, R. N., Mendonca, M., Yu, K., Deller, J., Stahl, G., \& Kurshid, A. (2000). Impact of culture on human resource practices: A 10-country comparison. Applied Psychology: An International Review, 49(1), 192-221.

Bachrach, D. G., Powell, B.C., \& Bendoly, E. (2004). Organizational citizenship and performance evaluations. The impact of task interdependence. Best papers proceedings 2004, Academy of Management.

Barksdale, K. \& Werner, J. M. (2001). Managerial ratings of in-role behaviors, organizational citizenship behaviors, and overall performance: Testing different models of their relationship. Journal of Business Research, 51, 145-155.

Barnard C. I. (1968). The functions of the executive. Cambridge, MA:Harvard University Press.

Baruch, Y., O'Creevy, M. F., Hind, P., \& Vigoda-Gadot, E. (2004). Prosocial behavior and job performance: Does the need for control and the need for achievement make a difference? Social Behavior and Personality, 32(4), 399-412.

Bateman, T. S. \& Organ, D. W. (1983). Job satisfaction and the good soldier: The relationship between affect and employee "citizenship." Academy of Management 
Journal, 26, 587-595

Bilgiç, R. (1999). A different way of testing the interaction between core job dimensions and growth need strength (GNS). Conference on TQM and Human Factors, 210215. CMTO, Linköpings universitet.

Blau, P. (1964). Exchange and power in social life. New York: Wiley.

Boonzaier, B., Bernhard, F., \& Braam, R. (2001). A review of research on the job characteristics model and the attendant job diagnostic survey. South African Journal of Management, 32, 11-24.

Borman, W. C. \& Motowidlo, S. J. (1997). Task performance and contextual performance: The meaning for personnel selection research. Human Performance, 10(2), 99109.

Borman, W. C., Penner, L. A., Allen, T. D., \& Motowidlo, S. J. (2001). Personality predictors of citizenship performance. International Journal of Selection and Assessment, 9, 52-69.

Brief, A. P. \& Motowidlo, S. J. (1986). Prosocial organizational behaviors. Academy of Management Review, 11, 710-725.

Champoux, J. E. (1991). A multivariate test of the job characteristics theory of work motivation. Journal of Organizational Behavior, 12, 431-446.

Coleman, V. I. \& Borman, W. C. (2000). Investigating the underlying structure of the citizenship performance domain. Human Resource Management Review, 10, 2544.

Çetin, M. Ö. (2004). Örgütsel Vatanda $\square$ lık Davranı $\square \imath$. Ankara: Nobel.

Dansereau, F. D., Cashman, J., \& Graen, G. (1973). Instrumentality theory and equity theory as complementary approaches in predicting the relationship of leadership and turnover among managers. Organizational Behavior and Human Performance, 10, 184-200.

De Jong, R. D., Mandy, E. G., \& Jansen, P. G. W. (2001). Openness to experience and growth need strength as moderators between job characteristics and satisfaction. International Journal of Selection and Assessment, 9, 350-356.

Dunham, R. B. (1976). The measurement and dimensionality of job characteristics. Journal of Applied Psychology, 61(4), 404-409. 